$\begin{array}{ll} & \text { Etnográfica } \\ \text { etnográfica } & \text { Revista do Centro em Rede de Investigação em }\end{array}$

Antropologia

vol. $16(1) \mid 2012$

Vol. $16(1)$

\title{
Trabalhos de margem no centro da urbe: o arrumador de automóveis
}

\section{Luís Fernandes}

\section{(2) OpenEdition \\ Journals}

\section{Edição electrónica}

URL: https://journals.openedition.org/etnografica/1363

DOI: 10.4000/etnografica.1363

ISSN: 2182-2891

\section{Editora}

Centro em Rede de Investigação em Antropologia

\section{Edição impressa}

Data de publição: 1 fevereiro 2012

Paginação: 5-30

ISSN: 0873-6561

\section{Refêrencia eletrónica}

Luís Fernandes, «Trabalhos de margem no centro da urbe: o arrumador de automóveis», Etnográfica

[Online], vol. 16 (1) | 2012, posto online no dia 23 março 2012, consultado o 12 fevereiro 2022. URL: http://journals.openedition.org/etnografica/1363 ; DOI: https://doi.org/10.4000/etnografica.1363

\section{(c) (i) (8)}

Etnográfica is licensed under a Creative Commons Attribution-NonCommercial 4.0 International License. 


\section{Trabalhos de margem no centro da urbe: o arrumador de automóveis}

\section{Luís Fernandes e Tiago Araújo}

O presente artigo centra-se na figura do arrumador de automóveis. Situa a sua emergência em relação com as manifestações e os atores que têm vindo, ao nível da rua, a protagonizar o fenómeno droga, e em torno dos quais os dispositivos de controlo social foram elaborando alguns dos principais elementos definidores do "problema da droga". A partir dos dados duma etnografia conduzida no centro de Guimarães, caracteriza então as rotinas da sua atividade, salientando o seu poder estruturador no quotidiano dos indivíduos, a dimensão relacional do estar na rua, destacando a interação com o automobilista, a organização territorial nos "parques" onde arrumam e a relação com as instâncias de controlo. O arrumador de automóveis é, a partir do que revelam os dados de terreno, conceptualizado como uma figura do trabalho informal e como um novo utilizados da cidade (city user), que vem da periferia social para participar, espacial e relacionalmente, no centro - e, nessa medida, ser também seu construtor.

PALAVRAS-CHAVE: arrumador de automóveis, trabalho informal, etnografia, droga, utilizador da cidade.

Margin works in the city centre: the informal parking attendant - This paper focuses on informal parking attendants. It locates the rise of such business in relation with street-drugs actors and their behaviours. It also considers the ways in which social control agencies have elaborated crucial dimensions of "the drugs problem" around informal parking attendants. Based on ethnographic work carried out in downtown Guimarães, the paper describes the routines of informal parking attendants, stressing the structuring effects of such business in the lives of the individuals who perform it. The relational realm of life in the streets, interactions with drivers, the territorial organization of parking places, and the attendants' relationship with control agencies are also emphasized. According to the empirical data, informal parking attendants are seen as underground economy workers and as a new type of city user: one that comes from the margins of society to take part, both in spatial and relational terms, in its centre. Thus, they can also be seen as builders of that centre.

KEYWORDS: informal parking attendant, underground economy, ethnography, drugs, city user.

FERNANDES, Luís (jllf@fpce.up.pt) - Faculdade de Psicologia e de Ciências da Educação, Universidade do Porto, Portugal

ARAÚJO,Tiago (tiagu_sousa@hotmail.com)-Centro de Ciências do Comportamento Desviante da Faculdade de Psicologia e de Ciências da Educação, Universidade do Porto, Portugal 
OS CONSUMOS PROBLEMÁTICOS DE DROGAS, SOBRETUDO QUANDO adquirem uma dimensão fortemente visível no espaço público, são um fenómeno que se tornou corrente nos sistemas urbanos. Mas nem por serem correntes perderam a carga com que são encarados, seja enquanto tema do debate social, seja enquanto preocupação de diferentes instâncias de controlo. Nas sociedades urbanas complexas os consumos problemáticos de drogas podem assumir expressões variadas, dizer respeito a grupos sociais muito distintos e a zonas muito diferentes entre si no que toca à sua visibilidade e ao modo como são percebidas como problema.

A construção do seu estatuto como problemático tem uma longa história, que poderíamos remontar à conquista espanhola da região que tem ainda hoje um grande protagonismo no panorama internacional das drogas: a região andina da folha de coca, reprimida então pelos espanhóis pela sua associação a cerimoniais religiosos incas (Diaz 1998; Escohotado 1996). Não traçaremos aqui o longo percurso que culminou com a ilegalização das substâncias a que hoje chamamos drogas e que teve como grandes eixos construtores os dispositivos jurídico-penal e médico-sanitário (Fernandes 1998; Lamo de Espinosa 1989; Romaní 1999). Pretendemos apenas sublinhar o atual estatuto problemático de certos produtos e de indivíduos, grupos sociais e zonas urbanas a eles associadas, normalmente referidos no seu conjunto no debate público como o "problema da droga".

Em Portugal, a visibilidade pública do "drogado" começou a ganhar contornos nos anos 70 do século XX e tornou-se presença constante na comunicação social a partir de meados dos anos 80, acompanhando o aumento do consumo de heroína e a fixação dos seus principais mercados de retalho nas "periferias degradadas". Diríamos que a comunicação social explorou o potencial fílmico de novas figuras que emergiam no espaço urbano, difundindo imagens e debates que erigiriam "a droga" como um dos mais preocupantes problemas com que Portugal se debatia. A melhor demonstração do alarme social assim gerado foi o rápido crescimento dos dispositivos de controlo em seu torno (cf. Agra 1993; Fernandes 2009, 2011 ).

O "problema da droga" teria assim, de acordo com a sua evolução na interface entre consumos de psicoativos ilegais e reação social, figuras que se iam tornando centrais: primeiro o "toxicómano juvenil" e o "traficante", depois o "toxicodependente", que por sua vez se desdobrava em figuras como o "heroinómano" ou a "prostituta-toxicodependente", passando também a distinguir-se entre o "traficante" e o "traficante-consumidor". Pelo meio destas figuras que concentravam as atenções dos mass media e do dispositivo de "combate à droga" surge, bem no centro de Lisboa e do Porto, um novo ator que depressa se percebeu estar também ligado ao "problema da droga": o arrumador de automóveis. 
É justamente a figura do arrumador aquela que concentrará a nossa atenção neste texto. Ele é o ator que materializou no contacto diário da rua a figura do "drogado", que o cidadão comum desenhava sobretudo a partir do relato da comunicação social. O arrumador é a interface com o comum utilizador da cidade; tem por isso um grande peso na produção de representações sociais sobre o "drogado", o "excluído", o "marginal". É uma personagem relativamente nova nos espaços urbanos - começamos a cruzar-nos com ela em Lisboa ou no Porto no início dos anos 90 -, proliferou rapidamente, mas nem por isso mereceu a atenção dos cientistas sociais que estudam a cidade ou o desvio. No final dessa década, as autoridades municipais estimaram em cerca de 700 o seu número nas ruas do Porto; em Lisboa, embora não houvesse números oficiais, calcula-se que seriam mais de 1500.

A inquietude provocada pela aparição dos arrumadores no quotidiano das cidades portuguesas deu origem, no final dos anos 90 no Porto, a uma primeira intervenção social, no quadro do contrato-cidade para o combate à exclusão social, o programa "Há Porto contigo"; a partir de 2002 iniciar-se-ia o Porto Feliz, também de iniciativa autárquica, cujo primeiro objetivo era o de os retirar das ruas e praças, de modo a restaurar a "normalidade" da cidade dominante. No debate público da altura, o arrumador aparecia como um potenciador do sentimento de insegurança: seria em regra um toxicodependente, e este era tido nos relatos diários da comunicação social como o principal responsável pelo "aumento da criminalidade". Viemos agora encontrá-lo em Guimarães. Esclareceremos na secção seguinte o porquê de ser nesta cidade e não em qualquer outra da mesma escala urbana.

\section{DELIMITAÇÃO DO OBJETO E ESCOLHAS METODOLÓGICAS}

A investigação que nos conduziria a centrar-nos sobre os arrumadores de automóveis teve origem numa solicitação por parte duma autarquia. Com efeito, a Câmara Municipal de Guimarães quis aprofundar o conhecimento sobre os consumos e os utilizadores problemáticos de drogas, de modo a potenciar as ações interventivas, tanto do seu departamento de ação social como das organizações que integram a rede social. Estávamos, portanto, perante o desafio de empreender um trabalho etnográfico junto dos atores e dos territórios das drogas em Guimarães. ${ }^{1}$

l Esta seria a parte qualitativa e, digamos, intensiva da investigação "consumo de álcool e drogas no concelho de Guimarães - estudos na população estudantil e consumidores problemáticos (implicações para a prevenção das toxicodependências)", solicitada pelo Município de Guimarães ao Centro de Ciências do Comportamento Desviante da Faculdade de Psicologia e de Ciências da Educação da Universidade do Porto em 2009. A outra componente da investigação, de natureza quantitativa e, digamos, extensiva, "caracterização dos padrões de consumo de álcool e de outras drogas na população estudantil do concelho de Guimarães", esteve a cargo do prof. Jorge Negreiros. 


\section{Delimitação do objeto}

Tarefa primeira: delimitar o objeto da pesquisa. Circunscrevemos os consumos problemáticos às franjas de indivíduos mais marginalizadas, que são normalmente aquelas em que os problemas sanitários e sociais atingem maior gravidade, sendo também as que se tornam mais visíveis nas dinâmicas diárias dos espaços urbanos. Do conjunto de dados que o trabalho de campo gerou isolaremos a parte que diz respeito aos indivíduos que optaram pela atividade de arrumador de carros como estratégia para tornar viável o financiamento dos consumos da(s) droga(s) a que estão adictos.

\section{A unidade de estudo}

Tarefa segunda: escolher a unidade de estudo. A opção pela pesquisa de terreno em contexto natural exige o contacto prolongado com atores e respetivos territórios. A existência dum território com grande centralidade, tanto face ao fenómeno droga como face à própria cidade, estava já previamente identificada por uma equipa de redução de riscos e minimização de danos. ${ }^{2}$

Recorremos então à equipa de rua como âncora de terreno, de modo a irradiar posteriormente a partir do seu local habitual de permanência, situado no centro histórico. Apesar da sua centralidade no mapa da cidade, tratava-se dum espaço intersticial: ao fundo duma viela, num pequeno largo fora das vistas dos transeuntes, com um túnel rodoviário que oferecia o recato de consumir resguardado dos outros e protegido do vento, o que se reveste de utilidade prática quando têm de acender-se isqueiros e aspirar finas colunas de fumo, que qualquer aragem faz dispersar. O decorrer do trabalho de campo confirmaria a importância deste território psicotrópico na organização diária dos utilizadores: local de consumo, de compra e venda de "produto", de relacionamentos e contactos, uma vez ou outra de pernoita (havia quem dormisse no túnel), de recurso aos serviços da unidade móvel de redução de riscos.

\section{O trabalho de campo}

A etnografia foi o método escolhido para levar a cabo os objetivos definidos para a investigação. Tem provado ser uma das estratégias metodológicas com maior capacidade de se acercar de realidades em relação às quais os grupos dominantes produzem distância social e simbólica. Esta distância redu-las a imagens simplificadas e simplistas - os estereótipos, que circulam como verdades de senso comum. Vários estudos têm caracterizado estes estereótipos a propósito da "droga" e dos "drogados", mostrando o seu reducionismo e o modo como funcionam como sentenças valorativas a priori (cf. Quintas 1997;

2 Referimo-nos à In-Ruas, projeto da Sol do Ave - Associação para o Desenvolvimento Integrado do Vale do Ave - que efetua trabalho de proximidade com consumidores problemáticos nas ruas do centro histórico de Guimarães desde o verão de 2008. 
Ribeiro 2004; Romaní 2009). A tarefa inicial do etnógrafo é suspender tais estereótipos, abordando os atores no seu contexto natural, nos lugares onde desenrolam a sua atividade quotidiana, procurando adotar a postura de quem pouco ou nada sabe do que vê e ouve.

A profundidade com que vem a poder conhecer-se um mundo social específico, nas pesquisas em contexto natural, depende do sucesso com que se processa a aproximação do investigador às zonas e aos grupos e indivíduos que quer conhecer. E esta proximidade dá-se pela conquista progressiva da sua confiança, pelo que a evolução é necessariamente lenta.

O primeiro problema a resolver é, desde logo, o de como entrar na zona que se escolhe, o de como abordar os indivíduos, o de como fazer-se aceitar por quem nada tem, aparentemente, a ganhar com a sua presença ali.

Ter a equipa de redução de riscos como âncora inicial permitiu beneficiar do capital de confiança que os seus técnicos já tinham construído no trabalho de proximidade com os utilizadores de rua. Mas o papel do investigador não deve, por razões éticas, ser ocultado, nem, por razões técnicas, pode ser confundido com o dos profissionais que trabalham na unidade móvel. Não estivemos ali, portanto, fazendo-nos passar por alguns deles. De resto, não estávamos sequer dentro da carrinha. Ela constituiu a possibilidade de, sem grande trabalho de aproximação prévio, aparecermos no meio dum primeiro conjunto de utilizadores de drogas, constituído pelos utentes mais ou menos regulares desta unidade móvel. À medida que fomos ganhando proximidade com alguns dos mais assíduos, foi então possível alargar a nossa observação a todo o centro da cidade, já que passámos a reconhecê-los em vários espaços e pudemos ir "ficando por ali" - pelas ruas centrais, pelas praças, pelas esquinas e, principalmente, pelos "parques", à medida que constatávamos que os indivíduos que conhecíamos da unidade móvel eram os mesmos que arrumavam carros nesses "parques". Sobre o que são e como estes funcionam, teremos tempo de ver já adiante.

Assim, os tempos iniciais duma pesquisa deste tipo são de negociação do estatuto do investigador, tanto junto dos técnicos como, principalmente, junto dos atores das drogas, etapa fundamental para que a sua presença não seja um obstáculo ao livre curso dos fenómenos nos seus settings naturais, sob pena de alterarmos irremediavelmente aquilo que queremos conhecer.

Fazer etnografia é, deste modo, estar sempre no começo: porque a unidade de estudo é nova, porque os atores são outros, porque o contexto exige novas adaptações. Os primeiros passos são sempre de incerteza, os primeiros contactos são sempre de descoberta:

"Entretanto o Renato (técnico da equipa de rua) diz, virando-se para mim, 'Este é aquele colega de que tínhamos falado que vinha uns tempos connosco', frisando bem que eu não pertencia à equipa, que estava a fazer um estudo para a universidade. O F., ainda no chão, com uma prata usada 
na mão, diz: 'É um estágio, não é, jovem? É um estágio...' Eu respondo: 'É mais ou menos isso [entre risos], é uma pesquisa para a Universidade do Porto...", dizendo o F.: 'É isso, é isso...' Quando o Renato diz o meu nome, eu estendo a mão ao F., que ma aperta” [diário de campo, primeiro dia].

O etnógrafo é apresentado aos primeiros utilizadores com quem se cruza. Inicia-se o processo de definição do seu estatuto naquele contexto, funcionando a intermediação do técnico de redução de riscos e a frase "é para a universidade" como apaziguadores da desconfiança que a sua presença causa.

"O R. está a desembrulhar com muito cuidado uma prata, e o Renato diz: 'Queres vir ver aqui o R., que ele não se importa que o vejamos a consumir?' O R. acrescenta: 'Eu não, não me importo nada...' Eu agradeço e aproximo-me deles. Vão falando, mas eu concentro-me naquilo que o R. está a fazer, acaba de desembrulhar a prata e no seu centro está uma mancha, que parece uma mancha de café coagulada. Com muito cuidado ele descola-a da prata e tomba-a para outra prata nova, depois raspa os restos, como que a tentar aproveitar ao máximo todos os bocadinhos que estavam na prata” [diário de campo, primeiro dia].

O etnógrafo obtém as primeiras autorizações para participar, observando diretamente a "cena drug", ainda com a intermediação do técnico de redução de danos. São os primeiros passos para que o vínculo que este já criou com os utilizadores de drogas seja transmitido ao investigador. A continuidade deste processo acabará por autonomizá-lo do intermediário, passando a ter acesso direto aos lugares e aos indivíduos, explicando uma e outra vez porque se encontra ali, caso note interrogação ou estranheza em algum deles. Verá então o utilizador no momento da consumação do interdito, ou o desvendar da privacidade que os mundos de rua também encerram:

"Chegamos perto da parede e o R. acende o isqueiro e dá uma passa. Observo que a mancha se liquidificou, se moveu e largou fumo, que foi aspirado pelo cano de prata. O R. pergunta-me, agachando-se de cócoras encostado à parede: 'Mas nunca tinha visto, é?' Eu respondo que não, e ele diz: 'Quer dizer, sabia o que é mas nunca tinha visto...' Eu volto a dizer que sim, e reparo que o Renato se afasta um pouco, percebo que era para não apanhar com o fumo. Eu também me afasto, mas consegui sentir o cheiro, era adocicado e esquisito" [diário de campo, primeiro dia].

Observar é uma experiência sensorial plena: há também odores, o etnógrafo regista como quem vê pela primeira vez. E nada do que vê é trivial, tudo interessa, precisamos de tudo quanto se ofereça diante de nós - porque, mais 
à frente, com o acumular dos dados, aquilo que parecia mero pormenor pode revelar grande valor informativo. Resistir às definições prévias, deixar para trás o estereótipo, fazem parte da arte de ver quando se está no terreno. São também as condições que permitem a emergência da novidade.

\section{SER ARRUMADOR}

A figura do arrumador de automóveis viria a ganhar, à medida que o trabalho de campo decorria, progressiva centralidade. Procuremos uma compreensão da sua presença nos espaços de rua que nos leve para além das evidências de senso comum. Quando chegamos perto dele, o que constatamos sobre este ator que se tornou presença diária em várias das nossas cidades? Que trajetória o trouxe até à rua? Que faz, em que consiste a sua atividade? Como se relaciona com o automobilista e com os comerciantes das imediações do seu "parque"? Quanto rende a atividade? Que faz ao dinheiro que vai recolhendo? E como reagem à sua presença constante os que têm de interagir com ele?

Não era, já o dissemos, nossa intenção inicial tomar o arrumador de automóveis como objeto de pesquisa. Fomos conduzidos até ele pela fidelidade a um dos princípios da investigação etnográfica: não impor ao objeto de estudo uma delimitação prévia. Estar, ao invés, preparados para nos adaptarmos às suas peculiaridades, seguir-lhe a pista, ir para onde ele nos for levando. E o que este princípio ditou foi que, começando a relacionar-nos com indivíduos que utilizavam a rua como local de compra e consumo da(s) sua(s) droga(s) preferida(s), acabámos por ir dar aos "parques": os lugares onde alguns deles passam uma grande parte da jornada a angariar dinheiro para poder comprar a substância a que estão adictos.

Que faz ele por ali no "parque" horas a fio? Num olhar superficial, no comentário do senso comum, parece não fazer mais do que entreter o tempo, tentando arranjar umas moedas "para a droga". O arrumador seria um indivíduo em errância, uma espécie de herdeiro atual da velha figura do vadio. Quando nos acercamos, porém, assemelha-se mais a uma figura do trabalho informal. O vadio está longamente inscrito na história das sociedades que consagraram o trabalho como a sua moral dominante, algo que foi ocorrendo com muito maior intensidade a partir da revolução industrial. Em Portugal, o século XIX é o século do "vadio", do "vagabundo", do "ocioso", do "pária" - o outro lado da moeda do operariado industrial, constituído sobretudo na segunda metade desse século a partir da migração maciça do campo para a grande cidade (Fatela 1999; Vaz 2006).

O código penal de 1886 define assim o vadio:

"Aquele que não tem domicílio certo em que habite, nem meios de subsistência, nem exercita habitualmente alguma profissão, ou ofício, ou outro 
mester em que ganhe a sua vida, não provando necessidade de força maior que o justifique de se achar nestas circunstâncias" (cit. em Fatela 1989: 89).

Em comum com o vadio, o arrumador tem também a circunstância de ser uma das vítimas da profunda transformação em curso, que já nos habituámos a chamar globalização e cujos efeitos nos mais variados setores da vida vão sendo descobertos sucessivamente. Esta transformação tem vindo a produzir novas desinserções, novas errâncias e novas marginalidades. A diferença em relação àquela época é que estas não são constituídas por aqueles que a lógica do trabalho deixou de lado, mas resultam da degradação deste nos países do capitalismo avançado (deslocalizações maciças, desregulação laboral, exploração de migrantes clandestinos, trabalho temporário, recrutamento ao dia, degradação salarial, desemprego...).

Quando traçamos a sociografia dos arrumadores que fomos conhecendo ao longo do trabalho de campo, todos eles do sexo masculino, notamos como têm, invariavelmente, percursos laborais intermitentes (entrecortados com desocupação), quase sempre em trabalhos pouco qualificados - os únicos a que podem ter acesso em função da baixa escolaridade de todos eles. É frequente a permanência pouco prolongada numa dada ocupação, com transições de trabalho em trabalho. Por exemplo, passar da construção civil a uma tinturaria, desta a uma tipografia; ou de talhante a operário fabril, da fábrica para a construção civil.

É também comum entre quase todos uma situação familiar, tanto da família de origem como da que formaram, marcada por conflito e roturas. A convergência entre esta e a degradação da situação face ao trabalho acaba por ter um desfecho também frequente entre os arrumadores com quem contactámos: a precariedade do alojamento, oscilando entre quartos de pensão, passagem temporária por casas de familiares e, não raramente, a situação de sem-abrigo.

O protagonista deste tipo de trajetória não é hoje, necessariamente, aquele que não se integrou na ordem da sociedade industrial, é o que vai sendo aos poucos vítima da desintegração do antigo mundo operário, da sua fragmentação, da subproletarização, que torna a relação entre as franjas populacionais mais expostas a estes processos e o trabalho cada vez mais improvável. ${ }^{3}$

Ao longo desta secção veremos como o arrumador traz a marca, ao nível individual, do processo a que acabamos de aludir: ele é a expressão de mecanismos macroestruturais que operam muito longe da sua vida, mas que a afetam profundamente. E é um exemplo de como os níveis macro e micro se ligam na análise social, e de como é difícil, no plano interventivo, operar mudanças no

3 A profunda alteração da estrutura do trabalho e do seu papel económico, social, afetivo e no plano dos valores está hoje amplamente analisada. Alguns autores têm feito a ligação deste processo com os atores e os fenómenos que recobrimos com a etiqueta "exclusão social”. Salientamos, a este respeito, as análises de Robert Castel (2000, 2004) e de Loïc Wacquant (2006). 
nível micro quando nada se altera no macro. Mas o paralelo entre o consumidor problemático/arrumador e o vadio para aqui. De facto, o que o arrumador faz assemelha-se mais ao trabalho do que àquilo que fazia o vadio - não fazia nada, definia-se pelo apego à ociosidade.

\section{Arrumar carros como atividade do trabalho informal}

"Esta preocupação com o bem-estar dos clientes, com a adoção duma atitude agradável que conquiste a confiança dos automobilistas, é um dos princípios mais respeitados pelos arrumadores com mais anos de carreira. Veem-se como profissionais que prezam a sua atividade e que procuram, de facto, prestar um serviço que consideram útil” (Fernandes e Pinto 2004).

Escrevíamos estas linhas há alguns anos, a propósito dos indivíduos, maioritariamente toxicodependentes, que arrumavam carros no Porto. Arrumar carros é um trabalho? José Machado Pais, numa das raras investigações que deram ao arrumador estatuto de objeto científico, diz-nos:

"Entre estes sujeitos existe uma consciência de grupo, um agir coletivo que se rege por um saber próprio e por uma ética de trabalho baseada no brio profissional, pelo que a preocupação expressa por alguns em respeitar os locais pertencentes a cada um e manter o seu território 'limpo' é disso exemplo" (Pais 2001: 245).

Também nós verificámos que os arrumadores com presença assídua nas ruas do centro de Guimarães se autopercecionavam como estando a prestar um serviço ao automobilista, comportando-se como quem executa um trabalho. Já não parece tão claro poder afirmar que o automobilista o percecione como um trabalhador, a avaliar pela quantidade dos que não "pagavam" o serviço...

O arrumador inscreve assim a sua presença numa espécie de trabalho informal, à semelhança do que acontece com outras atividades que, a despeito de serem olhadas como desviantes, marginais ou mesmo criminais, correspondem a verdadeiras ocupações, centrais na estruturação de modos de vida. Dê-se o exemplo da prostituição de rua, revelada na sua dimensão de atividade comercial, definindo a prostituta como trabalhadora sexual (cf., para o contexto do Porto, a etnografia conduzida por Alexandra Oliveira, apresentada em Oliveira 201 1); dê-se ainda o exemplo da venda ambulante levada a cabo por ciganos, estudada por Daniel Seabra (2006) em Lisboa. O facto de, no caso dos arrumadores, ser um serviço que não foi solicitado pelo cliente não lhe retira, pelo menos aos olhos de quem o realiza, o caráter de trabalho - também aqui à semelhança doutros, como as vendas por telefone ou porta 
a porta, muitas vezes, de resto, correspondendo a atividades do trabalho reconhecido e formal.

Não é este o lugar para aprofundarmos o conceito de trabalho informal. Mesmo assim, dada a centralidade que o arrumar carros desempenha enquanto atividade estruturadora da vida do indivíduo e, digamos, remunerada, vale a pena situar o conceito. Que o trabalho acabou por ocupar um lugar absolutamente fulcral à medida que a Modernidade avançou é algo que, pela exaustividade das análises que o demonstram, dispensa mais argumentação. E que as profundas mutações a que ele está sujeito na contemporaneidade estão a ter amplos reflexos nos equilíbrios sociais constitui um campo de análise de grande importância. Ora, o arrumador é disto um objeto-analisador: quase sempre um desempregado de longa duração, não perdeu o emprego duma vez. Foi, sim, resvalando nas posições que eram mais ou menos estáveis há umas décadas e que correspondiam a trabalhos pouco qualificados mas enquadrados na categoria social do operariado, sendo o produto da desagregação desta categoria nas sociedades pós-industriais. O mundo laboral a que pertencia ou foi desaparecendo como consequência da automação e da deslocalização ou se foi tornando instável, a sua baixa escolaridade constitui uma desvantagem muito maior do que há poucas décadas, saltar de ocupação em ocupação tornou-se comum, ficar sem trabalho também. A consequência foi a pauperização, e as tentativas de saída passaram pela emigração, ou pelo desempenho de tarefas em economias subterrâneas como a do mercado de retalho de drogas ilegais. Estas expectativas de saída de uma situação pessoal de grande vulnerabilidade revelaram-se com frequência apenas mais uma etapa no desenraizamento e na precarização.

Conseguir angariar o mínimo através dum empreendedorismo de margem correspondeu, no caso dos arrumadores, a uma reentrada no circuito da cidade. E é provavelmente por isso que se torna importante, olhado a partir do seu próprio ponto de vista, considerar que se está a realizar uma atividade, algo parecido com um trabalho. É o que mostra o terreno, quando analisamos em pormenor aquilo que fazem e como o fazem dia após dia no seu "parque". São, a nosso ver, uma figura emergente do trabalho informal. No quadro da atual desregulação, o trabalho informal começa a aparecer como uma categoria importante. Manuela Ivone Cunha situa o conceito de economia informal como tendo sido avançado há cerca de duas décadas

“[...] para qualificar [...] os rendimentos instáveis provenientes de atividades económicas fora do alcance regulamentar do Estado. Porém [...] convém precisar que Hart (o autor que propôs o conceito) se referia não a um setor definido de antemão e separável de outros, mas a fontes ou oportunidades de rendimento [...]. [Desde então,] a noção de informalidade tem sido profusamente utilizada em várias disciplinas (a sociologia, a antropologia, a economia, a geografia, a ciência política...)" (Cunha 2006: 220). 
À luz do que o trabalho de campo nos revelou, propomos o arrumador como figura emergente do trabalho informal. Para além da ausência de regulação das atividades económicas pelo Estado, a ausência duma lógica de mercado e/ou a ausência de legalidade seriam ainda características do trabalho informal, segundo a mesma autora. Este é suscetível, assim, de englobar uma multiplicidade de modalidades à margem do mercado formal. Inscritas onde, então? $\mathrm{Na}$ reciprocidade, parece-nos. Veremos adiante como a relação entre arrumador e automobilista pode revestir esta forma ancestral na troca económica e social. O que o arrumador evidencia, aplicando os termos de Manuela Ivone Cunha, é "um encastramento particular do económico nas relações sociais" (Cunha 2006: 221). Cheguemo-nos de novo à focagem de perto - vejamos os arrumadores do centro de Guimarães.

"Pedi um éclair e, ao pagar, perguntei à funcionária se ela tinha visto hoje o arrumador de carros que costuma estar ali. Ela disse que não e que ainda era cedo para ele, que deveria vir por volta das três e meia" [diário de campo].

A presença continuada dos arrumadores tornou-os familiares. As empregadas da confeitaria sabem a que horas "entra" o Manel. Porque trabalhar num "parque" tem bastantes parecenças com trabalhar noutro sítio qualquer do trabalho formal: atenção à tarefa (há alguma vaga para indicar ao automobilista que quer parar?), competências relacionais (interagir com o automobilista), fornecimento do serviço (por exemplo, ir à máquina, trazer o ticket, receber a moeda). De manhã, no mesmo parque, está o Canija. Horas certas para chegar, tal como o Manel de tarde - não há relógio de ponto, mas há o relógio biológico da ressaca, que é férrea a exigir pontualidade.

A máquina, nas economias formais, revelou-se devastadora dos postos de trabalho. Aqui, tanto pode ser aliada (dá mais rendimento arrumar em zona de parquímetros) como concorrente:

"O automobilista retirou o ticket e veio pô-lo dentro do carro. Parecia não ter intenções de dar nada ao Manel e este pergunta se ele não tem uma moeda. O homem disse-lhe que não tinha, que ia levantar e depois quando viesse que lhe dava. Quando se afastou de nós, o Manel disse, sorrindo: 'Vai levantar! Granda grupo, prefere dar dinheiro à puta da máquina em vez de a nós..." [diário de campo].

O arrumador que tem presença assídua num "parque" - geralmente "o seu parque" - conhece os ritmos dos utentes da zona, podendo assim tirar partido desses ritmos. O Barbas, por exemplo, sabe que à quinta-feira o seu parque está fraco quase toda a tarde, mas entre as 18 h30 e as 19 h30 há uma boa 
movimentação de automóveis que lhe permite, só nessa hora, fazer 6 ou 7 euros - o suficiente para a dose necessária para passar a noite. Ser arrumador implica portanto, a seu modo, um conhecimento do quotidiano da cidade:

"O Barbas disse que aquele sítio não era bom, que do outro lado é que era. Eu disse que do outro lado tinha parquímetros e que pensava que era pior. Ele respondeu que não, que o facto de ter parquímetros ajudava, pois as pessoas davam sempre 50 ou 20 cêntimos para eles tirarem os tickets. Disse que ali em uma ou duas horas se fazia 20 euros à vontade.

Perguntei-lhe ainda qual era o dia que dava mais dinheiro. Ele disse que era o sábado, porque as pessoas iam todas às compras e então os carros estavam sempre a sair e a entrar" [diário de campo].

Há porém outros horários bem menos lucrativos. Vimos locais igualmente centrais onde o arrumador que estava de manhã, entre as 8 e as 10 horas, apenas tinha amealhado dois euros. E quem dá mais moedas? Também aqui os arrumadores têm um saber feito de experiência. Vejamos a "teoria explicativa" do Rujo:

“Depois o Rujo ainda disse que os carros bons não davam nada e que podia aparecer um carro velho e a pessoa dava uma boa moeda. Ele justificou a sua teoria: 'As pessoas têm um carro e tudo, mas já o têm há muitos anos, não é, e sabem o que é viver com necessidades e dão uma boa moeda, agora os outros com mais posses não sabem e não dão nada..." [diário de campo].

A ajuda ao arrumador pode, na interpretação deste, radicar numa espécie de solidariedade saída da experiência direta das dificuldades.

Arrumar carros tem em comum com outros ofícios obrigar a perseverança e esforço, por vezes em condições severas do "ambiente de trabalho". Os dias frios e chuvosos são disso exemplo - e há que trabalhar, porque a ressaca não hiberna... Quando o dia está a correr mesmo mal, quando está difícil juntar a quantia para o pacote de heroína ou de base, lança-se mão, por vezes, da criatividade. Vejamos como é que o Canija resolveu o problema:

"O dia está a correr mal ao Canija, os carros não saem, os poucos que chegam não dão moeda. Chega então um, ele vai 'metê-lo' e, quando regressa, diz: 'Já tive que espetar uma mentira', dando a entender que era assim que se ia safando. Contou que tinha dito ao homem que hoje fazia anos e que ainda não tinha comido nada. Disse ainda que eram mentiras inofensivas e eu acrescentei que era uma estratégia, que ele tentou comover o automobilista para este the dar dinheiro. Ele concordou e disse que o senhor the tinha dado 2 euros" [diário de campo]. 
A vida na heroína cansa, arrumar carros também, as duas juntas desgastam. "Estou farto desta vida!" é uma frase corrente. "Para a semana vou começar um tratamento" também. E no dia seguinte estão no mesmo posto a arrumar os mesmos carros, vão trocar as moedas aos mesmos sítios, correm então a entregar a nota ao dealer para obter o pó do alívio imediato. Tanto cansaço pede descanso, todo o trabalho precisa de férias. Quando é que são as férias dum arrumador? Quando finalmente recolhe a uma comunidade terapêutica, quando é internado para uma desintoxicação. Às vezes, as férias vão passar-se a um estabelecimento prisional, quando finalmente há o desfecho dum processo por tráfico - algo que não é nada raro na trajetória de muitos.

O olhar distraído do habitante citadino achará provavelmente os arrumadores "todos iguais" - como temos tendência a fazer quando reduzimos a um estereótipo um grupo em relação ao qual produzimos distância social e simbólica. Mas, como em qualquer outra ocupação, os arrumadores exibem estilos pessoais ao executá-la. Estes estilos têm relação com a personalidade de cada um. Vejamos o que o etnógrafo anotou quando foi ver o Rujo a trabalhar no seu "parque":

"Nós estávamos na entrada do parque encostados ao tal carro. E entretanto tive a oportunidade de ver o Rujo trabalhar. Vagou um lugar mesmo ao nosso lado e ainda demorou uns minutos até aparecer um carro que lá estacionasse. Pensei que o Rujo se ia pôr à entrada do parque ou na rua principal a angariar, como o Manel, mas não, ele manteve-se ali perto do lugar. Foi um facto que constatei, o Manel é muito mais pró-ativo do que o Rujo, que não pressionava nada os condutores, não angariava carros para o lugar, esperando que aparecessem, e não corria para os lugares para ajudar as pessoas a estacionar.

[...] O Rujo estava a arrumar um carro quando cheguei perto dele, e pude vê-lo durante alguns segundos a trabalhar sem que ele me visse. Não notei diferença das vezes em que ele sabia que eu estava ali, pelo que deduzo que o estilo dele é mesmo aquele. É um estilo retraído e calmo, sem causar pressão nos condutores" [diário de campo].

Também o Barbas, que arruma num "parque" perto do Rujo, apresenta um estilo low profile:

“Eu fiquei ali com o Barbas e ele ia 'metendo' uns carros e conversando comigo. Fiquei parado e mantinha alguma distância quando ele interagia com os condutores. Tal como o Rujo, ele era bastante comedido, não pressionava os condutores e não era inconveniente" [diário de campo].

A vida no "parque" é rotineira. Uma das operações de rotina é a troca das inúmeras moedas que se vão acumulando nos bolsos por uma nota, pois é 
prática corrente os dealers não aceitarem moedas quando o arrumador lhes vai comprar a dose. O comércio local é o entreposto em que o arrumador faz a sua troca:

"O balcão do café era cinzento claro e tinha alguns utensílios de trabalho em cima. O Rujo despejou o porta-moedas, espalhando as moedas de forma a que não ficassem sobrepostas. E quando a empregada passou por nós ele tratou-a pelo nome e pediu um café. [...] O Rujo acabou de contar e ficou inquieto. Queria que lhe trocassem logo o dinheiro, pois podia perder o dealer. Olhou várias vezes para as funcionárias que andavam atarefadas com serviço de outros clientes. Os olhares dele eram como uma súplica para que se despachassem" [diário de campo].

Outras vezes, o arrumador tenta "enganar-se" nos trocos. Poucos cêntimos têm um grande valor, sobretudo se são os que faltam para perfazer o preço que paga por um pacote de heroína:

"Depois de estacionar, o Manel pediu-lhe uma moeda e o condutor, já fora do carro, disse-lhe que não tinha troco. O Manel disse que lhe trocava, se ele tinha uma nota de 5 euros. O rapaz disse-lhe que só tinha uma nota de 10 euros e o Manel, sorrindo, disse que também lhe trocava. Começou a contar as moedas e deu-lhe uma nota de 5 euros e algumas moedas para a mão e já estava a virar costas quando o rapaz lhe chamou a atenção, olhando para as moedas na palma da mão. O Manel voltou-se e meteu lá mais uma moeda, guardando depois no bolso da camisa a nota de 10 euros. Depois de o rapaz se ter ido embora, antes mesmo de lhe perguntar o que se tinha passado, o Manel disse: 'Estava a ver se lhe comia um euro, mas o cabrão reparou e assim só me deu 50 cêntimos!'” [diário de campo].

Mas, em geral, a relação é cordial e o arrumador tem oportunidade de mostrar as suas competências:

"Quando eu estava a pagar ao balcão, o Manel apareceu lá com uma nota de 5 euros para trocar. Brinquei com ele e disse-lhe que ele estava cheio de dinheiro. Ele disse que não era dele, que era de uma senhora que tinha estacionado o carro. Estava a pedir à funcionária para lhe trocar em moedas de 1 euro, que era para a condutora lhe dar 1 euro. [...] O Manel, a condutora e a filha desta falavam sobre deixar ou não a janela do Mercedes um pouco aberta, pois lá dentro estava um animal numa jaula de plástico que precisava de respirar. A senhora deixou a janela com um friso de ar aberto e o Manel passou lá os dedos e disse-lhe que não havia problema" [diário de campo]. 
A atividade até poderia tornar-se lucrativa, caso o arrumador conseguisse abandonar os consumos:

"O Barbas comentou acerca do indivíduo que estava naquele momento a 'trabalhar' naquele 'parque'. Disse que o indivíduo já não consumia, que estava a tomar metadona e que agora aquilo que ele fazia lá era tudo lucro. Que devia fazer uma 'pasta do caraças'. Disse o Barbas que o indivíduo the terá dito que em breve também ia deixar a metadona, que todos os meses reduzia um pouco quando ia à consulta" [diário de campo].

No entanto, esta situação não parece ser comum: a metadona não afasta necessariamente o indivíduo dos consumos de heroína, muito menos o afasta dos de base de coca, mantendo-se por isso a necessidade de financiamento para a sua compra. Uma visita ao terreno já depois de termos dado por terminada a observação sistemática mostrou-nos um Rujo à espera de ser chamado para um internamento, em mais uma tentativa de, não apenas parar com as drogas, como de mudar de vida, desgastado pelo cansaço. E disse que nessa altura poderia então, aí sim, juntar umas moedas e quando lá voltássemos seria ele a pagar um almoço.

Quanto rende esta atividade? Precisemos um pouco mais:

"Perguntei-lhe como tinha corrido o dia e ele disse que tinha corrido muito bem, que tinha feito 13 euros durante a manhã” [diário de campo].

Se se começar a atividade cedo, tem-se o dinheiro suficiente para o consumo imediato de heroína ainda antes do meio-dia. À tarde, o ciclo recomeça-porque a ressaca virá pontualmente e há que lhe impedir a chegada. Mas os ganhos são muito variáveis, dependendo da localização do "parque", do facto de haver ou não parquímetros, dos ritmos de certas atividades que trazem gente ao local, das condições meteorológicas - e, claro, das competências do arrumador, embora seja por enquanto inconclusivo sabermos qual dos vários estilos na relação com o automobilista se revela mais rentável.

Vários episódios têm-nos mostrado repetidamente que muitos dos arrumadores evidenciam responsabilidade na execução da tarefa, como se de um trabalho formal se tratasse. Vejamos o episódio em que o etnógrafo tenta obter do Manel uma entrevista sobre a sua trajetória nas drogas:

"Perguntei-lhe se podíamos fazer já a entrevista e ele ficou meio calado. Eu disse-lhe que lhe dava uns 3 euros pelo tempo que ele não ia arrumar carros. Respondeu-me que não era pelo dinheiro, mas sim pelos carros que lá estavam, que podiam apanhar uma multa. Perguntou quanto tempo 
demorava e eu disse-lhe que eram uns 20 minutos. Pediu então que esperasse um pouco para ele controlar os carros" [diário de campo].

Do repertório de competências faz também parte a cortesia:

"Perguntei ao Manel como é que ele fazia a abordagem. Ele disse que chegava lá e dizia 'boa tarde'. Num caso como o de agora - tinha acabado de receber moeda dum Mercedes - , ele dizia: 'Boa tarde, doutor'. Eu disse-lhe que perguntava aquilo pois havia outros tipos de abordagem em que contavam histórias intermináveis sobre acidentes de percurso e etc. Ele disse que era sempre bem-educado e que sabia falar, e que, quando as pessoas não iam na cantiga dele, também usava outros métodos para lhes dar a volta. Eu já assisti a esses métodos mais persuasivos por parte do Manel, enrola a conversa e diz que está tudo controlado, que controla a polícia, que podem confiar nele, etc." [diário de campo].

No trabalho formal há um equilíbrio entre a competição e a cooperação. Também aqui identificamos este binómio. Sobre a competição falaremos mais à frente a propósito dos territórios; a cooperação também acontece, porque a vida na rua também é relacional e cria laços:

"Pelo caminho perguntei-lhe se ele tinha deixado o tal rapaz arrumar na rua dele. Ele disse que sim, que habitualmente deixava que esse tal indivíduo fosse para lá das 5 às 6. Disse o Manel: 'Eu gosto de repartir a riqueza pelos pobres..." [diário de campo].

A pobreza é, de facto, um estado que apresenta uma certa relatividade...

\section{A relação com o automobilista}

A exploração etnográfica que José Machado Pais levou a cabo entre os arrumadores de Lisboa sintetiza numa frase o essencial do modo de vida de arrumador: "o seu caráter relacional, a sua dinâmica reguladora de quotidianos da marginalidade urbana e a sua função de subsistência económica" (Pais 2001: 247).

Também nós, nas notas de terreno, dávamos conta duma economia de subsistência, inspirando-nos na expressão que era utilizada para o campesinato pobre do interior norte de Portugal, em que o trabalho da terra dava apenas para o estritamente necessário à sobrevivência. Também anotávamos a função reguladora que o estar no "parque" a arrumar carros tem no quotidiano destes indivíduos - porque o trabalho é ocupação, e a ocupação estrutura o tempo objetivo e o subjetivo. E anotávamos com abundância o caráter relacional do estar na rua arrumando carros, como que devolvendo à cidade quem, doutro 
modo, poderia bem estar numa rota de isolamento e de invisibilidade. Este lado relacional aparece nas frequentes interações que os atores estabelecem com os automobilistas, com comerciantes da zona, com companheiros do ofício, com outros consumidores, com dealers. E, no caso de muitos deles, com a equipa de rua de redução de riscos e minimização de danos, com os técnicos do Centro de Respostas Integradas (a que ainda chamam CAT) e com outros serviços da rede formal de instituições. Dum modo muito sintético, diremos que este lado relacional se desenvolve segundo duas modalidades: a confiança e a tensão.

"Esperei mais um pouco até às $15 \mathrm{~h} 30$ e depois resolvi ir embora da confeitaria, mas ia perguntar algumas coisas às funcionárias. Quando estava a pagar perguntei se o Manel se dava bem com elas e apresentei-me como estando a fazer um trabalho sobre a toxicodependência para a universidade. Elas disseram que ele se dava muito bem com elas e que era muito prestável, que as ajudava com as compras, tendo uma delas piscado o olho e dito: 'Para poder comer!' Disseram também que lhes arranjava lugar para estacionar e que ele andava sempre apresentável, limpinho e que sabia falar. De vez em quando ia lá trocar dinheiro" [diário de campo].

A confiança é aquilo que permite o vínculo social, estando portanto na base da vida coletiva. Os grandes espaços urbanos geraram padrões interativos defensivos, mais caracterizados pela indiferença e pelo anonimato do que pela confiança. Mesmo assim, os indivíduos e os grupos desenvolvem estratégias para minimizar o efeito desse traço da vida urbana, pois apesar da grande cidade continuamos a ser animais de pequeno grupo e de relação face a face.

Ora, o arrumador parece ter-se tornado um especialista deste relacionamento face a face, personalizando um espaço que doutro modo seria um mero sítio de passagem e para-arranca de automóveis. É certo que força com frequência a interação, é certo que é da experiência de qualquer pessoa sentir que preferia não ter de trocar alguma frase e, ainda menos, dar uma moeda. Mas é certo também que esta postura do arrumador contribui para quebrar o anonimato e a indiferença: com o passar dos dias conhece muitos automobilistas mais ou menos frequentes no seu "parque" e, com alguns, desenvolveu mesmo uma relação de confiança:

"Disse que um automobilista que tinha estacionado num dos lugares que estavam afastados de nós lhe pagava o pequeno-almoço de vez em quando. Disse que ele o deixava pago e que depois ele ia lá comer. Às vezes não comia nesse dia e comia no outro" [diário de campo].

Com alguns automobilistas a relação de confiança mútua vai ao ponto de ser o arrumador a realizar a gestão do aparcamento: 
"Vi esse indivíduo dirigir-se a um carro que acabou de estacionar, a condutora pela janela aberta disse-lhe algo e ele foi à máquina tirar um ticket. A mulher não the deu dinheiro algum. Fiz essa observação ao Barbas e ele disse que era assim. A pessoa estacionava e depois dizia ao arrumador quanto tempo queria e este ia tirar o ticket, pagando do bolso dele. Depois a pessoa dava-lhe uma moeda que cobrisse o investimento e que desse mais algum. Imaginemos que a pessoa pedia um tempo que custava 50 cêntimos, depois podia dar ao arrumador 1 euro e este lucrava 50 cêntimos. O Barbas disse que até podia ser mais. E se o arrumador tivesse já um talão ainda com tempo de validade, que era só lucro" [diário de campo].

A confiança pode exprimir-se sob a forma de solidariedade, sobretudo quando o contexto envolvente apela a este comportamento social:

“Depois perguntei como é que estava a correr o dia e ele sorriu dizendo que estava a correr muito bem, que já tinha feito 20 euros desde as 14 horas. Eu sorri e fiquei espantado, mas depois disse, ao mesmo tempo que o Manel, que era por ser Natal. Ele disse que as pessoas diziam: 'Pegue lá um euro, que é Natal"” [diário de campo].

O Natal é para todos; em menos de duas horas o Manel juntou 20 euros.

\section{A tensão}

A relação com o automobilista é por vezes sentida por este como incomodativa:

"Um dos carros que ele arrumou chamou-me a atenção, não pelo carro, mas pela atitude do Manel, que é a sua forma de estar. Era uma jovem condutora. O Manel dava-lhe as orientações dizendo: 'Assim, jovem, assim, anda assim, anda'. Ele estava à frente do carro, e como a condutora estava a fazer a manobra de outra forma ele insistia e não saía da frente do carro. Elevou o tom da voz nas suas indicações. A jovem, no interior do carro, 'passou-se' e gritou para ele sair da frente do carro, levando as mãos ao ar. Ele acabou por sair e a condutora acabou de estacionar. Não lhe deu nada, tendo ido à máquina tirar um ticket" [diário de campo].

Os nossos dados de terreno não mostram o centro de Guimarães como palco de tensões entre arrumadores e automobilistas. Se bem que pontualmente a interação possa ser confrontativa, no geral ocorre num clima que releva mais da confiança do que da tensão. Não conhecemos o histórico da atividade na cidade. Mas levantamos a hipótese, que seria necessário testar com dados empíricos, de que o estilo dos arrumadores se modificou em relação 
aos tempos em que começaram a aparecer pelas ruas - tomamos aqui como referência os do Porto, baseando-nos na nossa experiência de frequentadores da cidade e numa investigação etnográfica com arrumadores cujo "parque" era a Loja do Cidadão das Antas (Matias e Fernandes 2009). Com efeito, inicialmente, o estilo de abordagem era com frequência confrontativo, no caso de negada a moeda podia tornar-se hostil e abundavam os relatos de ter sido danificada a pintura do automóvel como retaliação. Vem provavelmente daqui a associação da figura do arrumador com o sentimento de insegurança, algo que os próprios reconhecem quando dizem saber que são temidos como uma ameaça para o automóvel, enquanto o toxicodependente (que também são...) seria sentido como uma ameaça para as pessoas (Matias e Fernandes 2009).

Parece hoje diferente a interação dos arrumadores com os automobilistas, o que provavelmente se relaciona com dois fatores: por um lado, o cidadão foi-se habituando à sua presença e não confirmou os receios iniciais que esta figura, por ser tida como "drogado", inspirava; por outro lado, os próprios arrumadores foram constatando que era mais eficaz, porque mais rentável, uma abordagem pautada pela cordialidade, desincentivando deste modo tanto neles como nos colegas de ofício atitudes que possam gerar desconfiança ou receio no automobilista.

A observação mostrou-nos, no Porto, como alguns não iam para o "parque" antes de cuidar minimamente da apresentação (por exemplo, fazendo a barba), e como repreendiam colegas que enganassem ou tentassem roubar algum "cliente" (Fernandes e Pinto 2004; Matias e Fernandes 2009). Pois bem, também agora verificámos o mesmo. E acrescentaremos que, se o cuidar da apresentação é uma estratégia calculada, também o apresentar-se com um aspeto descuidado, sujo ou a indiciar más condições de vida é considerado por alguns como uma estratégia eficaz para obter ajuda. Os "asseados", digamos, criticam os "sujos" por darem má imagem da atividade e estes defendem-se da acusação invocando o pragmatismo da sua estratégia... Afinal, verifica-se o mesmo que em qualquer outra atividade laboral em que a maioria dos seus profissionais tenta minimizar a má imagem causada por uns poucos, coisa que temos verificado, por exemplo, numa outra figura típica de qualquer cidade, o taxista.

\section{Territórios}

"Quando chegámos perto da rua do Manel vi que estava lá um outro indivíduo a arrumar carros, conseguia ver a sua silhueta curvada e os gestos característicos. Pensei que o Manel ia disparar para recuperar o seu território, mas ele não reagiu, parecia que já sabia. Antes de chegarmos mais perto perguntei-lhe e ele apenas disse que estava lá esse rapaz, que o tinha deixado arrumar uns carros mas que ele se ia já embora. 
Ao chegarmos perto do rapaz, o Manel falou com ele. Eu fui um pouco mais para longe. O Manel foi logo para o início da rua e começou a angariar carros, pois havia um lugar vazio, ele assobiava e apontava" [diário de campo].

A distribuição espacial dos arrumadores não é casual nem aleatória. Pelo contrário, os espaços têm valores estratégicos diferentes, uns rendem mais do que outros, pelo que os indivíduos exercem um controlo sobre o seu território, de modo a não o deixar apropriar por outros. A rua, para os arrumadores, tem dono - e cada um manda no seu "parque”. É, aliás, da experiência comum de quem usa a cidade diariamente notar que os arrumadores são sensivelmente os mesmos nos mesmos sítios, contribuindo com esta constância para a rotina urbana. O que a observação detalhada mostra é que não estão ali passivamente, como quem se limita a esperar que da sucessão dos automóveis que vão estacionando resulte o pecúlio que precisam de amealhar para cada dose. Ser arrumador é ser ativo: angariar automobilistas, estar atento aos lugares que vão vagando, interagir com o dono da viatura, exercer domínio sobre aquele espaço que não querem largar para a concorrência:

“O Manel ia dizendo para ele ir embora, para ir para outro sítio. E ele respondeu-lhe que dava para os dois, que metiam um carro cada um. O Manel disse-lhe que não dava, que às vezes nem para um dava, quanto mais para dois. Depois apareceu um carro e o rapaz começou a correr em direção ao lugar. O Manel também ia para lá, mas depois ficou a meio do caminho e deixou-o ir. Veio ter comigo meio a resmungar, a dizer que se davam 'abébias' e que depois o pessoal abusava. Eu perguntei-lhe se o rapaz era amigo dele e ele disse que sim, e que era por isso que ele ainda ali estava, se não já o tinha corrido" [diário de campo].

E porque estava ali aquele arrumador? Não tinha território e procurava ocupar um? A resposta veio logo a seguir:

"Perguntei-lhe se o ADM era novo e ele disse que devia ter cerca de 25 anos, e que o conhecia por viverem perto. Depois perguntei-lhe se o ADM não tinha uma rua dele para estacionar e ele disse que sim, que era num parque perto da estação, só que um automobilista andava atrás dele porque o ADM ficou de vigiar para tirar um ticket caso viesse a polícia e depois o homem foi multado. O ADM saiu de lá sem tirar o ticket" [diário de campo].

E porque se ausentou o ADM, desleixando o capital de confiança que o "cliente" tinha depositado nele? Porque completou a quantia para a dose e a 
ansiedade da compra, a pressa de consumir, se sobrepôs ao dever "profissional”. Quem é que ainda não se escapou alguma vez mais cedo do trabalho?

Como se consegue um território, como se fica sem ele? Não pudemos aprofundar estas circunstâncias, mas sempre ficamos com uma pista ao ouvir o caso do Manel:

"Continuamos a falar acerca dos lugares de estacionamento. Eu perguntei se, quando ele tinha ido para aquela rua, não estava lá ninguém. Ele disse que não, que costumava estar lá um fulano, mas que depois desapareceu. Ele tomou a rua e depois, passado um ano, o fulano apareceu e queria a rua outra vez. Combinaram que um ficava de manhã e o outro ficava de tarde, sendo que o Manel ficava de tarde. Depois perguntei-lhe quanto tempo é que era preciso uma pessoa não aparecer para lhe poderem tomar o lugar. Ele respondeu que era uma semana. Eu disse-lhe então que se ele ficasse doente uma semana era um risco. Ele depois reconsiderou e disse que uma semana se calhar era pouco tempo, mas que se fosse um mês ou dois, ou seis meses, aí já não havia hipótese" [diário de campo].

Eis aqui um importante inconveniente do trabalho informal: não dá direito a baixa médica...

Ter-se apropriado dum território apresenta, para além da vantagem óbvia de saber que se tem um sítio, a vantagem de poder criar uma relação com pessoas habituais na zona:

"Perguntei-lhe como era ao sábado e ele disse que ali era muito fraco e lembrei-me que o Barbas me tinha dito que na rua ao lado era o melhor dia. Perguntei-lhe porque é que não tentava outros sítios e ele disse que não, que preferia ir para o mesmo sítio porque era mau mudar, já que se estivesse sempre no mesmo sítio as pessoas iam-no conhecendo e que assim ele estabelecia uma relação com as pessoas e deste modo já davam "boas moedas". Perguntei como é que ele tinha chegado a essa conclusão, se tinha experimentado outros sítios e ele disse que sim, que começou a pensar que, se ficasse sempre no mesmo sítio, as pessoas começavam a ganhar confiança com ele" [diário de campo].

O território é também um espaço de interconhecimento, fornece uma base para as relações, mesmo que minimalistas. Apropriação, interconhecimento e relação aproximam o "parque" do lugar, no sentido antropológico do termo: muito mais do que um espaço neutro, é um sítio investido e significativo.

"Ao chegar lá avistei logo o Speedy Gonzalez e o Rujo. Estavam em sítios diferentes, sendo que estavam trocados, ou seja, o Rujo estava no sítio do 
Speedy Gonzalez e o Speedy Gonzalez no local onde costuma estar o Rujo. [...] Fui ter com ele e quando lá cheguei cumprimentámo-nos. Fiz-lhe a observação da troca de lugares e ele disse que ali não havia lugares fixos, que tanto podia estar ele como o Speedy Gonzalez, que era quem chegasse primeiro. Que agora estava ele ali naquele lugar, e que daqui a cinco minutos podia ir para lá o Speedy Gonzalez" [diário de campo].

Os "parques" dos arrumadores podem, portanto, configurar-se como territórios secundários: não são exclusivos, são ocupados segundo a regra "primeiro a chegar, primeiro a usar". Esta regra exacerba a concorrência, obrigando quem quer manter o seu posto a não se desleixar no horário e na continuidade. O trabalho informal exige iniciativa, o indivíduo tem de defender o seu próprio interesse, ninguém o faz por si - neste aspeto, o arrumador assemelha-se a um profissional liberal...

\section{Arrumadores e controlo social formal}

Arrumadores e polícias municipais trabalham ambos no mesmo setor: a regulação do aparcamento urbano. É natural, portanto, o modo pouco simpático como os arrumadores olham os polícias:

"O Manel começou por fazer queixa de um polícia que o andava a aborrecer por ele estar a arrumar carros. Disse ele que o polícia lhe disse: 'Não podem estar arrumadores onde está a polícia'. Ele diz que disse ao polícia: 'Olhe, então vá dar uma volta que eu fico aqui...'” [diário de campo].

Olham para os polícias como tendo critérios discricionários em relação a quem pode estar estacionado, numa espécie de sistema de privilégios que mostra aos arrumadores o quanto estão afastados do verdadeiro controlo da rua que pensavam sua:

"O D+ foi à máquina dos tickets, presumo para tirar um ticket para pôr em algum carro, depois quando estava ao pé de nós disse: 'Queres ver que o gajo vai me foder os tickets... vai ser direitinho, foda-se'. Vi que depois o polícia estava a chamá-lo à atenção acerca de um dos carros. O D+ não mostrou grande reação, apenas falou com ele e vi que sorriu.

O Canija começou a resmungar, dizendo: 'Filhos da puta, só multam a quem lhes interessa, esteve ali um Opel Corsa a manhã toda, só porque era do $[\ldots]$ '. Ele disse que havia carros que eram dos polícias, que estavam estacionados o dia todo, mas que nunca tiravam o ticket. Disse também que estava ali um carro, que era do café onde eles iam tomar o pequeno-almoço, e que também não multavam" [diário de campo]. 
Encontramos nos arrumadores do centro de Guimarães um dado que é recorrente nos grupos que se dedicam a atividades desviantes, ou ajuizadas dum modo negativo pelo discurso dominante: a desconfiança perante as instâncias e as figuras do controlo social, imputando-lhes frequentemente o desfrutar de privilégios ilegítimos, ou seja, a ideia de que mesmo os que seria suposto defenderem a ordem quebram as normas. Também nos arrumadores detetamos o uso da "condenação dos condenadores", uma das cinco técnicas de neutralização que Matza (1964) identificou.

Tendo a polícia o mandato de assegurar a ordem nos espaços públicos, tendo o ordenamento jurídico as atividades ligadas a determinadas substâncias psicoativas como ilícitas e tendo tantos consumidores problemáticos a rua como contexto privilegiado, os (des)encontros entre "ordem" e "desvio", entre "lei" e "crime" não são apenas inevitáveis - são frequentes e expectados de parte a parte. O tema foi surgindo nos relatos espontâneos ao longo do nosso trabalho de campo, tendo como argumento as detenções seguidas de revista, a descoberta de um ou vários pacotes (conforme se é consumidor ou também se anda a vender), a ida para a esquadra. $\mathrm{E}$, por vezes, um desfecho que os utilizadores consideram negativo e sobre o qual falam com alguma revolta: a destruição do produto mesmo à sua frente quando estavam a precisar dele como "de pão para a boca”. A situação mais extrema é, porém, a agressão física. Registemos a seguinte passagem do diário de campo:

"Depois eles falavam de alguém que andava todo partido, que tinha sido agredido. Uns diziam que tinha sido a polícia, outros diziam que tinha sido o gajo que lhe metia as cenas para ele vender - um dos ciganos ou outros.

Passado pouco tempo desta conversa chegou o Manetas e eu percebi pela cara dele que era dele que falavam. Tinha um olho todo esmurrado e uma sobrancelha inchada. Vinha com um boné que tapava a maior parte. Quando chegou fez uma entrada catita, anunciando a sua chegada, dizendo:

- Boa tarde pessoal, que aqui vem o homem!

Perguntaram-lhe logo o que se passava e ele disse:

— É para verem a autoridade que a gente tem, é a autoridade portuguesa!

- Mostrou as mazelas ao pessoal, e o Andrúsio perguntou se ele tinha apresentado queixa, se ele tinha ido ao juiz. Ele disse que sim, mas que os polícias disseram à juíza que tiveram de o agarrar, porque ele estava a ressacar e a dar com a cabeça na parede. À volta o pessoal falava sobre o sucedido" [diário de campo]. ${ }^{4}$

4 A violência policial tem sido testemunhada por técnicos de muitas equipas de rua. Desenvolvemos este tema a propósito dum outro território, nos bairros sociais da zona oriental do Porto. Remetemos para Fernandes e Ramos (2010), onde, a partir da investigação etnográfica, se faz um exercício de relacionamento entre a exclusão social, as violências quotidianas e a violência estrutural. 
O exercício da violência sobre indivíduos ou grupos marginalizados é a faceta mais aguda das consequências do estigma social. Viver na margem é sofrer de invisibilidade - mesmo que se esteja, como é o caso dos arrumadores, em espaços altamente visíveis. E é esta invisibilidade que torna invisível a violência de que são alvo. O arrumador está consciente da sua situação de desacreditado - para tomar a expressão de Erving Goffman a propósito daquele que é atingido pelo estigma:

"Enquanto subíamos a rua, o Rujo continuou a conversa que estávamos a ter e disse que as pessoas depois podiam comentar por me verem com ele. Eu disse-lhe que não havia problema, que não me importava com o que as pessoas pensavam, e ele disse: 'Muito bem, o que importa é o que fazes e não o que as pessoas dizem e pensam... acho bem, acho bem! É que nestes sítios pequenos..." [diário de campo].

Fica por esclarecer se esta autoconsciência do estigma social deve a sua maior quota-parte ao ser arrumador ou ao ser toxicodependente - o que, como se foi tornando claro com os nossos dados de terreno, são estatutos que andam próximos.

\section{NOTA FINAL: A EMERGÊNCIA DUM NOVO UTILIZADOR DA CIDADE}

Se compararmos a reação inicial que os arrumadores de automóveis suscitaram, bem traduzida no acionamento dos planos autárquicos para lhes fazer face que referimos na secção introdutória, com a aparente normalidade com que estão hoje integrados nas rotinas do espaço público, aplicar-lhes-emos a frase que Fernando Pessoa criou para a Coca-Cola: primeiro estranha-se, depois entranha-se. É isso: a sua presença inicial é um corpo estranho - no sentido literal. Um corpo que carrega a marca a partir da qual construímos os nossos estereótipos de marginalidade, um corpo atingido pela droga, que lhe inscreve sinais visíveis e reconhecíveis.

Mas a sua presença continuada impõe o arrumador à cidade, que, se primeiro o estranha, depois entranha-o. Eis o que parecem revelar os dados da investigação que conduzimos em Guimarães: mostram a sua naturalização na paisagem urbana, evidenciando-o como um novo tipo de utilizador da cidade.

O utilizador da cidade (city user) é um conceito dos estudos urbanos para designar o indivíduo típico da fase de metropolização das cidades, responsável pelas suas novas centralidades: o turista, o homem de negócios que circula entre centros financeiros, o consumidor de cultura e de ciência - circuito dos congressos, das exposições, dos festivais... (cf., por exemplo, Baptista e Pujadas 2000). O utilizador da cidade vem do centro para construir centro. Ora, o arrumador, o sem-abrigo, o migrante clandestino são também característicos 
da metropolização, ocupam e usam a cidade - e mostram como o centro também se constrói a partir da margem.

Os arrumadores fazem parte, portanto, dos circuitos relacional e económico da cidade - eis algo que a nossa investigação não descobriu, posto que qualquer frequentador atento da urbe pode concluir o mesmo, sem recurso a mais nada para além do seu poder de observação. Pertencem ao circuito relacional porque estabelecem interface com o cidadão que frequenta as ruas e praças onde se desenrola a vida ordinária; ao circuito económico, porque são atores do trabalho informal: dedicam-se a arrumar carros, é o seu tipo de empreendedorismo; e aplicam parte desse dinheiro a comprar drogas, contribuindo para um outro tipo de empreendedorismo, o dos dealers. Funcionam, portanto, como intermediários entre o dinheiro do cidadão comum que estaciona o seu carro e os atores das economias subterrâneas: o arrumador branqueia o dinheiro ao contrário, leva-o do lado legal para o ilegal. É a metáfora do lado pobre do neoliberalismo: têm um "trabalho" flexível e incerto, fazem circular a moeda, e o capital que lhes passa pelas mãos não passa pelas mãos do fisco...

Os especialistas dos estudos urbanos, como Hannerz ou Martinotti (cit. em Baptista e Pujadas 2000), sinalizam as principais categorias de atores sociais na cena urbana metropolitana contemporânea. Mas, se excetuarmos o migrante do terceiro mundo, pouco ou nada se referem a figuras da margem. Os especialistas da cidade interessam-se mais pelo diurno do que pela sombra? Estendamos nós o conceito de utilizador da cidade àqueles que, embora sem reconhecimento, embora desinscritos das existências valorizadas, também constroem a paisagem com que a cidade se oferece.

\section{BIBLIOGRAFIA}

AGRA, Cândido da, 1993, "Dispositivos da droga: a experiência portuguesa”, em C. da Agra (org.), Dizer a Droga, Ouvir as Drogas. Porto, Radicário, 29-47.

BAPTISTA, Luís, e Juan PUJADAS, 2000, “Confronto e entreposição: os efeitos da metropolização na vida das cidades”, Fórum Sociológico, 2. a série, 3-4: 293-308.

CASTEL, Robert, 2000, "A precariedade: transformações históricas e tratamento social”, em M.H. Soulet (org.), Da Não-Integração. Coimbra, Quarteto, 21-38.

—, 2004, "Encuadre de la exclusión”, em S. Karsz (org.), La Exclusión: Bordeando Sus Fronteras. Barcelona, Editorial Gedisa, 55-70.

CUNHA, Manuela I., 2006, "Formalidade e informalidade: questões e perspectivas", Etnográfica, X (2): 219-231. 
DIAZ, Aurélio, 1998, Hoja, Pasta, Polvo y Roca: El Consumo de los Derivados de la Coca. Barcelona, Universitat Autònoma de Barcelona.

ESCOHOTADO, A., 1996, História Elemental de las Drogas. Barcelona, Editorial Anagrama. FATELA, João, 1989, O Sangue e a Rua. Lisboa, Dom Quixote.

__, 1999, "Les mille visages du vadio portugais", em A. Gueslin e D. Kalifa (orgs.), Les exclus en Europe, 1830-1930. Paris, Les Éditions de l'Atelier, 49-58.

FERNANDES, Luís, 1998, "Os princípios da exclusão da droga", em H. Gomes de Araújo, P. Mota Santos e P. Castro Seixas (orgs.), Nós e os Outros: A Exclusão em Portugal e na Europa. Porto, Sociedade Portuguesa de Antropologia e Etnologia, 63-78.

—

— 2011 , "Terapias punitivas e punições terapêuticas: o estranho caso do "toxicodependente", em M. Ivone Cunha e Jean-Yves Durand (orgs.), Razões de Saúde: Poder e Administração do Corpo, Vacinas, Alimentos, Medicamentos. Lisboa, Fim de Século, 39-56.

FERNANDES, Luís, e Marta PINTO, 2004, "El espacio urbano como dispositivo de control social: territorios psicotrópicos y políticas de la ciudad", Monografias Humanitas, 5: 147 -162 .

FERNANDES, Luís, e Alexandra RAMOS, 2010, "Exclusão social e violências quotidianas em 'bairros degradados': etnografia das drogas numa periferia urbana”, Toxicodependências, $16(2): 15-29$.

LAMO DE ESPINOSA, Emilio, 1989, Delictos sin Victima: Orden Social y Ambivalencia Moral. Madrid, Alianza.

MATIAS, Margarida, e Luís FERNANDES, 2009, "Desarrumar o medo... O arrumador de carros como figura do medo na cidade”, Toxicodependências, 15 (3): 9-22.

MATZA, David, 1964, Delinquency and Drift. Nova Jérsia, Transaction Publishers.

OliveIrA, Alexandra, 2011 , Andar na Vida: Prostituição de Rua e Reacções Sociais. Coimbra, Almedina.

PAIS, José Machado, 2001, Ganchos, Tachos e Biscates: Jovens, Trabalho e Futuro. Porto, Ambar.

QUINTAS, Jorge, 1997, Drogados e Consumos de Drogas: Análise das Representações Sociais. Porto, Faculdade de Psicologia e de Ciências da Educação da Universidade do Porto, dissertação de mestrado.

RIBEIRO, Marcos, 2004, Representações Sociais das "Novas" e "Velhas" Drogas e Seus Consumidores: No Encalço da Deslocação/Alteração dos Padrões de Consumo. Porto, Faculdade de Psicologia e de Ciências da Educação da Universidade do Porto, dissertação de mestrado.

ROMANÍ, Oriol, 1999, Drogas: Sueños y Razones. Barcelona, Ariel.

—, 2009, "Criticando estereótipos: jovenes, drogas y riesgos", comunicação ao congresso "Hablemos de drogas, famílias y jovenes, juntos por la prevención", Barcelona.

SEABRA, Daniel, 2006, "Mercados encobertos: os ciganos de Lisboa e a venda ambulante", Etnográfica, X (2): 319-335.

VAZ, Maria João, 2006, “Gatunos, vadios e desordeiros: aspectos da criminalidade em Lisboa no final do século XIX e início do século XX”, em P. Almeida e T. Marques (orgs.), Lei e Ordem: Justiça Penal, Criminalidade e Polícia - Séculos XIX-XX. Lisboa, Livros Horizonte, 84-101.

WACQUANT, Loïc, 2006, Parias urbains. Paris, La Découverte. 